\title{
Lipoma in Hard Palate-A Case Report
}

\author{
Prince Peter Dhas, Ravindran Ambika, Amirthagani Arumugam, Jagan Somasundaram \\ Department of ENT, Thanjavur Medical College, Thanjavur, India \\ Email: drprincembbs@gmail.com
}

Received 19 February 2015; accepted 12 March 2015; published 17 March 2015

Copyright @ 2015 by authors and Scientific Research Publishing Inc.

This work is licensed under the Creative Commons Attribution International License (CC BY).

http://creativecommons.org/licenses/by/4.0/

(c) () Open Access

\begin{abstract}
Lipoma is a benign neoplasm of the soft tissue that originates in mature adipocytes. Even though it is a very common tumor, it is relatively uncommon in oral cavity. It represents about $1 \%$ to $4 \%$ of all benign tumors in oral cavity (12). This article describes a case of a 39 years old male with an intraoral pedunculated mass in the right side of hard palate which was histopathologically proved as a simple lipoma.
\end{abstract}

\section{Keywords}

Hard Palate, Lipoma, Benign, Oral Cavity

\section{Introduction}

Lipomas are benign mesenchymal neoplasms composed of mature adipocytes usually surrounded by a thin fibrous capsule [1]. Lipomas can occur in any part of the human body, but the majority occur in trunk and neck [2]. They can present as a single swelling or multiple swellings. About $20 \%$ occur in the head and neck region and only $1 \%$ to $4 \%$ involve oral cavity [3] [4]. Half of oral lipomas are in the cheek and the remaining are found in the tongue, floor of the mouth, lips, palate, and gingival mucosa [5]. Lipomas are usually asymptomatic till they grow to a larger size and interfere with speech, mastication and swallowing [6]. Lipomas may occur sporadically or as one of the several inherited disorders such as familial multiple lipomatosis and benign symmetric lipomatosis [7].

Based on their histopathological aspects, lipomas can be characterized as classic lipoma, fibrolipoma, intramural lipoma, spindle cell lipoma, angiolipoma, sialolipoma, pleomorphic lipoma, myxoid lipoma and atypical lipoma. The malignant counterpart of the tumor is liposarcoma which is an another common soft tissue neoplasm but rare in oral cavity [8].

\section{Case Report}

A 39 years old male patient presented with a mass in the oral cavity. A small swelling appeared in the right side of the palate before 6 years which progressively increased in size. He had problems with speech and mastication. 
He is a tobacco and betel nut chewer for 20 years. Physical examination revealed a soft pedunculated mass of size $6.5 \times 3.5 \mathrm{~cm}$ arising from the right side of the hard palate at about $1 \mathrm{~cm}$ medial to right 2nd molar. It was covered with intact mucosa. With the aid of computed tomography, bony attachments/erosion was excluded. Also the mass failed to enhance with contrast. Complete surgical excision was done and the mass was subjected for histopathological examination. Macroscopically the resected mass was yellowish in colour. Microscopic appearance shows a well encapsulated tumor composed of muscle fat cells with vacuolated cytoplasm with intervening fibrous septae. There was no sarcomatous change. The wound healed well. The patient was followed up for 1 year without any recurrence (Figures 1-6).

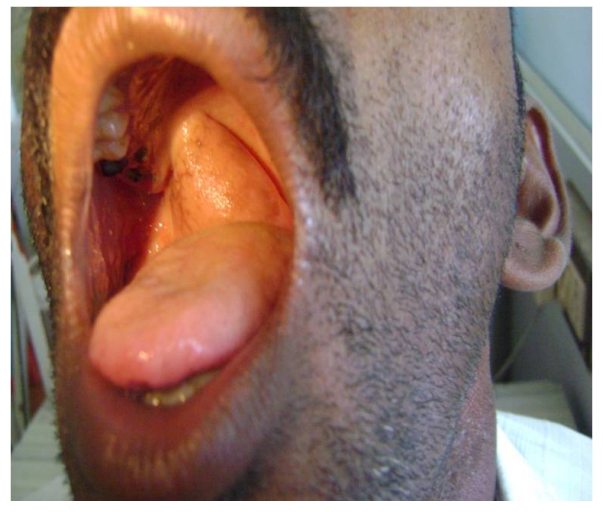

Figure 1. Showing mass in the hard palate.

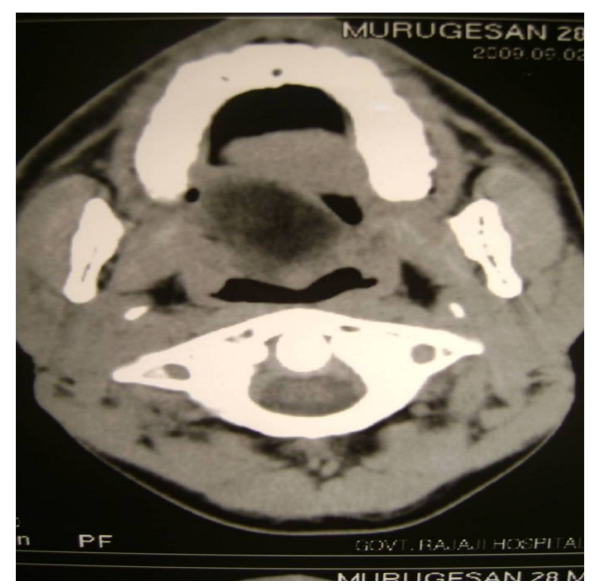

Figure 2. CT showing hypodense mass in hard palate.

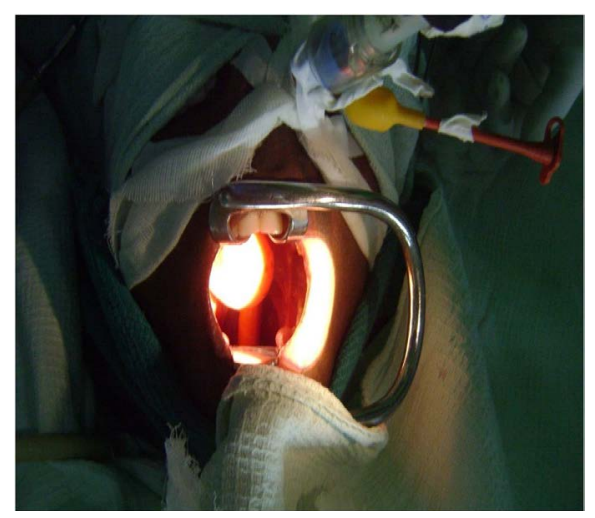

Figure 3. Preoperative picture. 


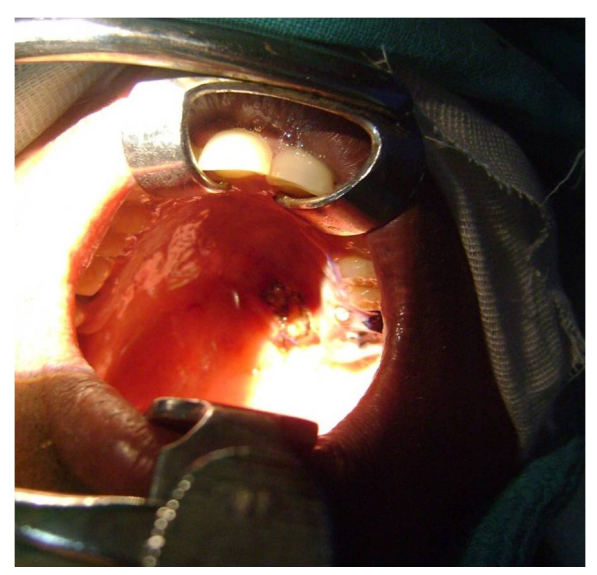

Figure 4. Post operative picture.

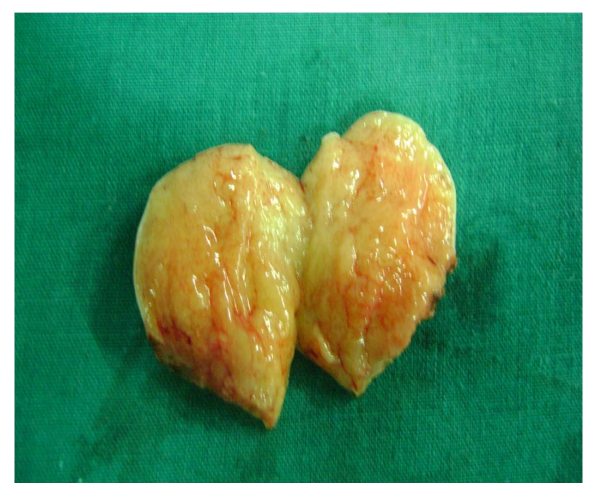

Figure 5. Cut section of excised mass.

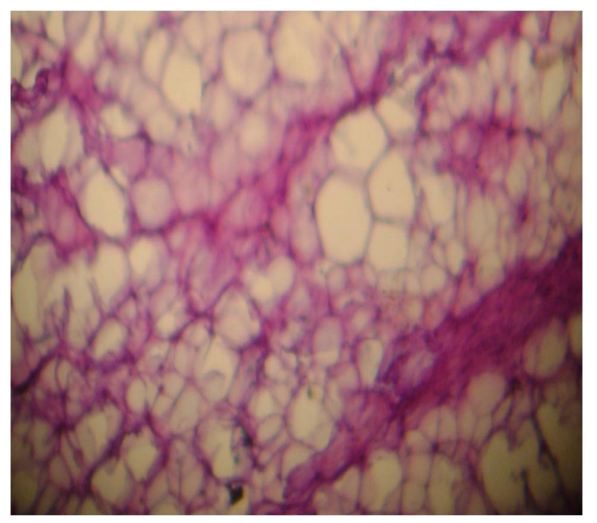

Figure 6. Microscopic picture showing mature adipocytes.

\section{Discussion}

The first oral lipoma was described by Roux in a review of alveolar masses in which he referred it as "Yellow Epulis" [9]. Lipoma is the commonest and most benign of all tumors. Intraoral region is a rare site for its development. The incidence does not differ with gender but a predilection for men has been reported [10]. The case we are presenting is very rare because of its site of attachment i.e. Hard palate. To the best of our knowledge only 2 cases of lipoma in hard palate mucosa has been reported (Hoceini et al., 2010; Sushruth Nayak \& Prachi Nayak) [11]. In a case series by Perez et al. on oral lipoma among 2270 cases of oral lesions in a period of 8 years, 6 cases were oral lipomas. Of the 4 , 3 were reported to be in buccal mucosa, 1 in lower lip, 1 in tongue 
[12].

Clinically oral lipomas generally present as mobile, painless submucosal nodules with a yellowish colour. In our patient it is a pedunculated mass which is a rare presentation.

The pathogenesis of lipoma still remains with lack of consensus. Various concepts such as obesity, hormonal influences, trauma and chronic irritation have been proposed [13].

Histopathologically our case is a classical lipoma which has been reported to be the commonest intraoral form in various literatures. Freital et al. (2009) reviewed 26 cases of intraoral lipomas and classic lipoma was the most common among them i.e. in 15 cases [14].

Surgical excision is the suggested treatment modality and if adequately resected, recurrence is rare. We followed the patient for 1 year without any recurrence.

\section{Conclusion}

We present this case for its rare site, size and presentation. A clinician must also recognize other differential diagnoses for such a mass which are to be excluded by radiological and histopathological examination to proceed with the correct treatment.

\section{References}

[1] Fregnani, E.R., Pires, F.R., Falzoni, R., Lopes, M.A. and Vargas, P.A. (2003) Lipomas of the Oral Cavity: Clinical Findings, Histological Classification and Proliferative Activity of 46 Cases. International Journal of Oral and Maxillofacial Surgery, 32, 49-53. http://dx.doi.org/10.1054/ijom.2002.0317

[2] Rosai, J. (1989) Ackerman’s Surgical Pathology. 7th Edition, The C.V. Mosby Co., St Louis, 1573-1579.

[3] de Visscher, J.G. (1982) Lipomas and Fibrolipomas of the Oral Cavity. Journal of Oral and Maxillofacial Surgery, 10, 177-181.

[4] Gnepp, D.R. (2001) Diagnostic Surgical Pathology of the Head and Neck. WB Saunders, Philadelphia.

[5] Vindenes, H. (1978) Lipomas of the Oral Cavity. International Journal of Oral Surgery, 7, 162-166. http://dx.doi.org/10.1016/S0300-9785(78)80019-2

[6] Keskin, G., Ustundag, E. and Ercin, C. (2002) Multiple Infiltrating Lipomas of the Tongue. Journal of Laryngology Otology, 116, 395-397. http://dx.doi.org/10.1258/0022215021910906

[7] Bradon, J.H., Blackwell, S.J., Mancoll, J.S.O., et al. (1999) Another Indication for Liposuction: Small Facial Lipomas. Plastic and Reconstructive Surgery, 103, 1864-1867. http://dx.doi.org/10.1097/00006534-199906000-00008

[8] Favia, G., Maiorano, E., Orsini, G. and Piattelli, A. (2001) Myxoid Liposarcoma of the Oral Cavity with Involvement of the Periodontal Tissues. Journal of Clinical Periodontology, 28, 109-112. http://dx.doi.org/10.1034/j.1600-051x.2001.028002109.x

[9] Manjunatha, B.S., Pateel, G.S. and Shah, V. (2010) Oralfibrolipoma-A Rare Histological Entity: Report of 3 Cases and Review of Literature. Journal of Dentistry, 7, 226-231.

[10] Furlong, M.A., Fanburg-Smith, J.C. and Childers, E.L. (2004) Lipoma of the Oral and Maxillofacial Region: Site and Subclassification of 125 Cases. Oral Surgery, Oral Medicine, Oral Pathology, Oral Radiology, and Endodontology, 98, 441-450. http://dx.doi.org/10.1016/j.tripleo.2004.02.071

[11] Nayak, S. and Nayak, P. (2011) Lipoma of Oral Mucosa: A Case Report. Archieves of Orofacial Sciences, 6, 37-39.

[12] Bandéca, M.C., de Pádua, J.M., Nadalin, M.R., Ozório, J.E., Silva-Sousa, Y.T. and da Cruz Perez, D.E. (2007) Oral Soft Tissue Lipomas: A Case Series. Journal of the Canadian Dental Association, 73, 431-434.

[13] Demir, Y. and Aktepe, F. (2002) Unusually Large Intraoral Submucosal Lipoma. The Medical Journal of Kocatepe, 3, 61-65.

[14] Freitas, M.A., Freitas, V.S., Lima, A.A.S. and Pereira Jr., F.B. (2009) Intraoral Lipomas: A Study of 26 Cases in a Brazilian Population. Quintessence International, 40, 79-85. 